\title{
OMAE2018-78237
}

\section{HYBRID TOOL TO PREVENT SHIP PROPELLER EROSION}

\author{
T. Llull \\ M. Castells \\ X. Martínez de Osés \\ Nautical Sciences, UPC, \\ Barcelona, Catalunya
}

Marine Engineering Laboratory,

UPC, Barcelona, Catalunya

Department of Engineering and Nautical

Sciences, UPC, Barcelona, Catalunya

\author{
A. Martín \\ Department of Engineering and \\ Nautical Sciences, UPC, \\ Barcelona, Catalunya
}

\author{
A. Mujal-Colilles \\ Marine Engineering Laboratory \\ UPC, Barcelona, Catalunya \\ X. Gironella \\ Marine Engineering Laboratory \\ UPC, Barcelona, Catalunya
}

\author{
A. Sánchez Arcilla \\ Marine Engineering Laboratory \\ UPC, Barcelona, Catalunya
}

\section{ABSTRACT}

The present contribution aims to implement a new methodology to prevent Roll on-Roll off vessels (RO-RO) from causing severe scouring actions. The methodology combines field, experimental, theoretical and numerical tools exchanging information to establish the manoeuvre potential scouring damage. The main contribution is the introduction of a manoeuvre ship simulator to obtain variables that otherwise cannot be obtained in field studies. These variables, all related to ship's propeller behaviour, are the rotational speed, the pitch ratio and the engine power during the whole manoeuvre.

Results show an over-prediction of the theoretical and experimental axial velocity and maximum erosion depth, indicating their clear limitations and the necessity of accurate data to apply the method. The methodology used with the key incorporation of the manoeuvre simulator is revealed to be a very useful tool to study new manoeuvres (including the possibility to work with a single or a couple of tugboats during the docking and undocking manoeuvres) to prevent propeller scouring actions.

Keywords: Erosion processes; propeller-generated scour; velocity measurements; AIS data; numerical tools; ship simulator.

\section{INTRODUCTION}

The shipping industry evolution over the last decades has led to growing structural and operational problems, particularly for old marinas designed to host ships with lower drafts. The increase in capacity, size, power and self-propulsion of present ships is the main cause behind morphodynamic sea bed changes in harbour basins. This is producing two different but linked problems: scouring effects near the structures, affecting their stability, and sedimentation of the scoured material in other areas of the basin, reducing the average depth and potentially causing the ship motions to become uncontrollable. Previous studies have concluded that the highest erosion problem comes from regular vessels, excepting tugboat and pilot operations [1].

The scouring issue has been investigated from the last decades up to our days from different approaches ([1]-[7]). The experiments carried out so far and resumed in a specific PIANC publication about propeller erosion, [2], use mainly a single propeller at bollard pull condition considering the undocking maneuverer. Besides, most of them are performed for free ducted and non-confined propellers, while ships always performed berthing and unberthing manoeuvres near quay structures which can magnify the scouring potential. The study of propeller generated erosion in confined environments has been also studied, though, in [8], [9].

During the manoeuvre and the navigation through the harbour channel, ships generate a propeller-induced wash, which affects 
the seabed depending on the engine power, the acceleration, the ship's characteristics and the propeller, together with local environment and met-ocean conditions (current, waves, wind and sediment type) [10].

The main research in ship's propeller-induced current applied to marine and harbour management has been carried out through laboratory experimental analysis, such as [11]-[13]. They based their work in the momentum theory, which has set the basis for most of the maritime engineer research made up to our days.

In the case of RO-RO vessels, due to their characteristics and operational needs, they are especially relevant when talking about scouring action. These vessels usually perform short voyages, so they dock and undock frequently, at the same harbours and quays. Moreover, these vessels need a L-shaped quay to allow their ramping mechanisms to be used during the port operations. Thus, during the manoeuvre, there is at least one main propeller which is throwing the wash perpendicularly to the vertical stern-quay. This effect, which is continuously repeated, can be compared with the effect of a constant wash impacting on the structure [8].

In the present study, a new methodology is presented to evaluate the case of a RO-RO quay scouring affectation and to check which of all the pre-existing formulation is valid to predict the scouring effect at a concrete quay, from real data of a specific vessel.

\section{STUDY CASE}

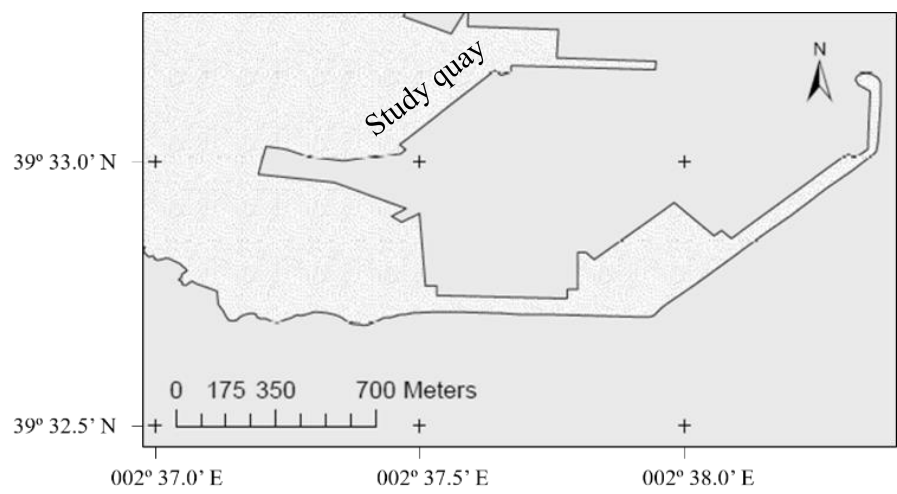

Figure 1. Study quay map.

One of the most used dockings by RO-RO vessels in the Port of Palma (Balearic Islands) is Paraires quay (Figure 1), which is 10 to 12 meters depth according to the Port Authority. The vessel considered in this study is one of the RO-RO ships docking there regularly. Vessel particulars are very common among the ferry type ships, regarding both dimensions and propulsion characteristics. The study-vessel is 199 meters in length, 36 meters in beam and her maximum depth is 6.4 meters. The ship is also equipped with two propellers which are 5.1 meters in diameter, rotate at velocities near to $130 \mathrm{rpm}$ and are connected to a $13000-\mathrm{kW}$ engine each.
The available sediment data (Table 1) was obtained by the Port Authority in a sampling campaign (2015) using VibroCores and Van Veen dredges at the nearest quay from the study docking (Figure 1).

Table 1. Sediment characterisation.

\begin{tabular}{cccc}
\hline $\mathrm{d}<0.063 \mathrm{~mm}(\%)$ & 33.76 & $\mathrm{~d}_{50}(\mathrm{~mm})$ & 0.16 \\
$\begin{array}{c}0.063 \mathrm{~mm} \leq \mathrm{d} \leq 2 \\
\mathrm{~mm}(\%)\end{array}$ & 55.28 & $\rho_{\mathrm{s}}\left(\mathrm{kg} \cdot \mathrm{m}^{-3}\right)$ & 2000 \\
$\mathrm{~d}>2 \mathrm{~mm}(\%)$ & 10.96 & $\begin{array}{c}\text { Sediment Volume } \\
\left(\mathrm{m}^{3}\right)\end{array}$ & 8840 \\
\hline
\end{tabular}

The campaign showed a first $0.5 \mathrm{~m}$ layer in which the sediment had the previously showed characteristics, but at that depth the gravel appeared, and diameter and density data were not studied. For this study, gravel diameter has been considered to be $2 \mathrm{~mm}$ and density has been considered to be between 1800 and 2200 $\mathrm{kg} \cdot \mathrm{m}^{-3}[14]$.

The most recent bathymetry of the study area dates from 2008 and has been taken as a reference (Figure 2).

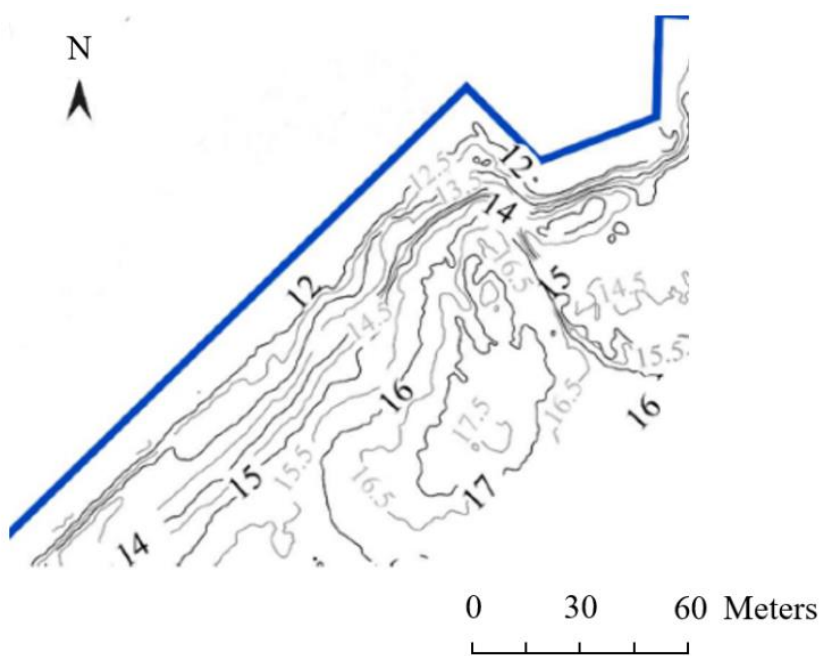

Figure 2. Study-quay bathymetry. Zoom in at the docking zone.

Wind is the most changing and more relevant meteorological variable when manoeuvring, mostly in big size vessels with big freeboard. Due to the orientation, the most harmful wind directions for the study quay are NW and SE winds, perpendiculars to it. As per historical data from [15], most affecting winds would be the ones from NW which, instead less frequent, are considerably intense so they may affect the manoeuvres.

\section{METHODOLOGY}

Figure 3 shows the proposed box scheme to combine different sets of data. The field campaign is proposed as a starting point to obtain in-situ current velocity measurements at the study quay 
during the manoeuvres and AIS data from the vessel. After the manoeuvres, AIS data from the vessel is used to obtain geographical position and ship behaviour and to link it with measured current values. The main point is to obtain the ship position and orientation when the current values are maximum. Once the data is obtained, they are analysed to reproduce the manoeuvres with the aid of Transas NTPro 5000-v-5.35 simulator. By reproducing the manoeuvre, the simulator yields the needed variable values during the manoeuvre time to apply the existing formulae. With the formulae main current velocity values and associated potential scouring action can be predicted. So far, the methodology is divided in three different subsections: field campaign, manoeuvre simulator and formulae application.

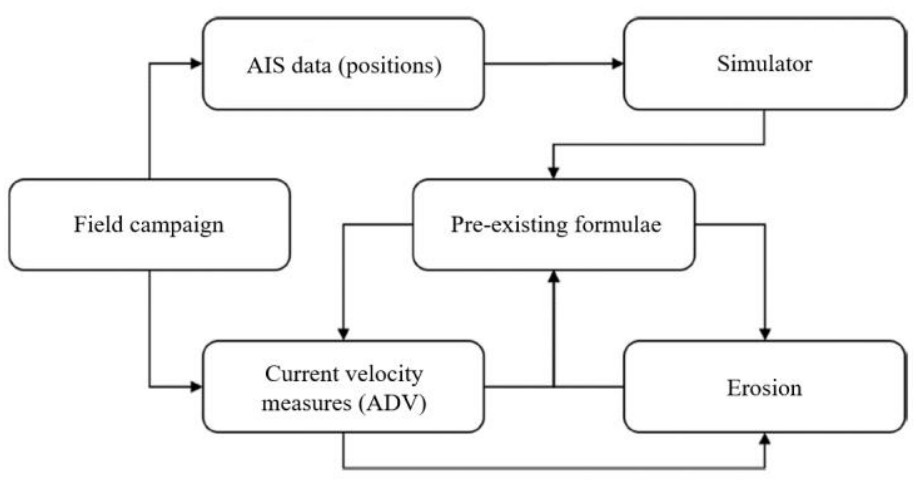

Figure 3. Methodology diagram.

\section{Field Campaign}

On the April $4^{\text {th }}$ and $5^{\text {th }}$, current velocity values were obtained during the ship manoeuvres at the study quay by means of an Acoustic Doppler Velocimeter (ADV). Figure 4 shows the scheme of relative distances among the quay, the propellers and the measurer. The measurer's position responds to operational needs during the campaign.

ADV measures were sampled at $8 \mathrm{~Hz}$ (sampling rate) and were located at 3.1 meters depth. Once analysed, data was smoothed with a Savitzky-Golay filter, which allowed to obtain a cleaner signal.

Wind velocity and direction values were obtained from the Spanish Meteorological Agency (AEMET) tide gauge (39³3.6' $\mathrm{N}, 002^{\circ} 38.4^{\prime}$ E) [15]. Data showed values of the wind during the campaign lower than $10 \mathrm{~km} / \mathrm{h}$, so wind was neglected.

AIS related data (vessel's position, speed over ground (SOG), heading (HDG), course over ground (COG), rate of turn (ROT), time UTC) were recorded during the manoeuvres to later be plotted on a GIS support to obtain precise results about the vessel's behaviour and to be able to relate vessel's position and actions with ADV recorded data.

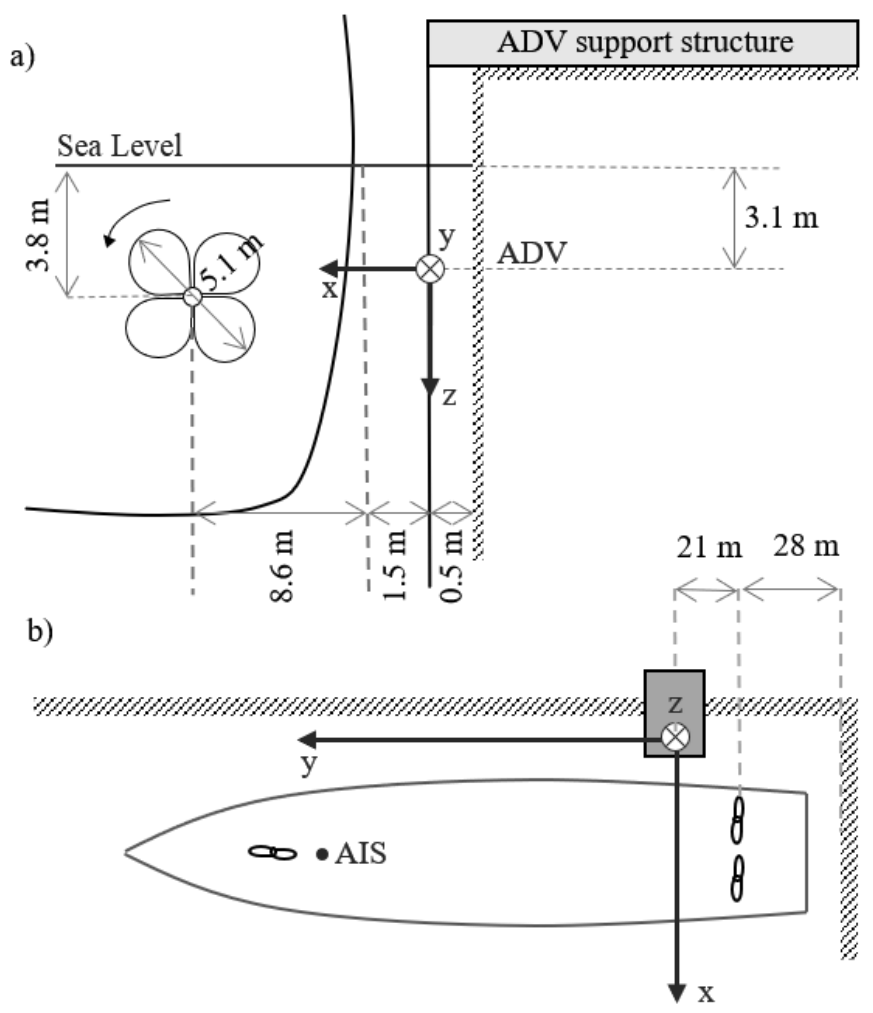

Figure 4. Vessel, quay and measurers relative distances and positions during the campaign.

\section{Manoeuvre simulator.}

Table 2. Comparison between study and simulator vessel. Main characteristics.

Variable

Gross Tonnage (GT)

Maximum beam (m)

Depth (m)

Freeboard (m)

Maximum draft (m)

Maximum length (m)

Length between

perpendiculars $(\mathrm{m})$
Study Vessel

Vessel dimensions

Propeller characteristics

Number of main engines

Indicated power $(\mathrm{kW})$

Number of propellers

Number of blades per

propeller

Propeller diameter (m)

Propeller type

Delivered power $(\mathrm{kW})$

Propeller centroid depth (m)

Maximum engine R.P.M.

Maximum propeller R.P.M.

Rotational direction
25993

27

9.6

3.2

6.4

198.99

177

Simulator Vessel

21104

25.5

16.62

6.5

182.6

166.29

2

11520

12775

2

4

5.1

CPP

11640

3.8

500

137

Inward
2

4

5.0

CPP

-

4

510

130

Inward 
Transas NTPro 5000-v-5.35 simulator has been designed to be used in naval and maritime engineering and coastal management to consider changes and modifications related to vessel's sea operations during docking and undocking manoeuvres. Due to the impossibility to perform the manoeuvres in the simulator with the study vessel, another RO-RO with very similar particulars has been used. Table 2 shows the comparison of the main variables between the two vessels.

\section{Pre-existing formulae.}

\section{Efflux velocity}

One of the most important parameters in the used formulae is the efflux velocity, $V_{0}$, which can be obtained from two different approaches. First approach uses the momentum theory as the basin to obtain $\mathrm{V}_{0}$ using equation (1):

$$
V_{0}=C_{1} \cdot n \cdot D_{p} \cdot \sqrt{C_{t}}
$$

Different authors consider the coefficient proposed by Albertson as a changing coefficient $C 1$ as shown below (Table 3 ).

Table 3. Coefficients proposed by different authors to compute efflux velocity Eq. (1)

\begin{tabular}{cc}
\hline Author & $\mathbf{C}_{\mathbf{1}}$ \\
\hline Hamill, G. [13] & 1.33 \\
Stewart, D. [16] & $\mathrm{D}_{\mathrm{p}}^{-0.0686} \cdot \mathrm{p}^{1.519} \cdot \beta^{-0.323}$ \\
\hline
\end{tabular}

[2] proposes a second expression, Eq. (2), to permit the $V_{0}$ calculation using the engine power instead of Thrust coefficient $\left(C_{t}\right)$, a shape-propeller dependent variable which is sometimes difficult to obtain:

$$
V_{0=} C_{2} \sqrt[3]{\frac{f_{p} \cdot P}{\rho_{w} \cdot D_{p}^{2}}}
$$

Finally, [17] proposes Eq. (4) which, similarly to the Eq. (2), gives out the $\mathrm{V}_{0}$ as a function of the engine power, among other variables.

$$
V_{0=1,17} \sqrt{\frac{P}{\rho_{w} \cdot D_{0}^{2}}}
$$

Results obtained from previous formulae are considered valid for the axial velocity calculation within the flow establishment zone (up to an axial distance of $2.5 D_{p}$ ) [11], [18].

\section{Flow velocity along the axis}

Flow velocity along the propeller axis is considered to be a function of efflux velocity, $V_{0}$. [19] proposes Eq. (4), where the coefficients ( $A, a$ ) changes depending on the authors (Table 4).

$$
V_{e i x}(x)=A \cdot V_{0} \cdot\left(\frac{D_{p}}{x}\right)^{a}
$$

Table 4. Coefficients of Eq. (2) depending on the author

\begin{tabular}{lrr}
\hline Author & A & $\mathbf{a}$ \\
\hline Albertson, M. [19] & 6.17 & 1 \\
German Method & 0.9 & 0.25 \\
Dutch Method & 1.95 & 1 \\
\hline
\end{tabular}

\section{Seabed velocity}

When the flow impacts on a vertical wall or quay, it is deflected all-around [20]. PIANC guides, [2], are based on [12], [21], after the in-situ analysis performed by [22], which purpose that flow velocities near the seabed are a function of the efflux velocity and can be calculated with the following expression (Eq. 6):

$$
\frac{L}{h_{p b}} \geq 1.8 \quad U_{b, \max }=2.8 \cdot V_{0} \frac{D_{0}}{L+h_{p b}}
$$

\section{Erosion depth formulae}

[1] results show that formulation proposed by [13], [8] provides consistent results with the observed erosion obtained from periodic bathymetry campaigns at some western Mediterranean harbour. The equations proposed by [8], [13], [23] yield the maximum erosion depth in confined and no-confined flux condition as a function of Froude densismetric number, propeller diameter, sediment characteristics and relative distances between the propeller, the wall and the seabed.

$$
\begin{gathered}
d_{\infty}^{u}=\Omega \cdot\left(\ln \left(t_{\infty}\right)\right)^{\Gamma} \\
d_{\infty}^{u}=45.04 \cdot 10^{-3} \cdot \Gamma^{-6.98} \cdot\left(\ln \left(t_{\infty}\right)\right)^{\Gamma} \\
\Gamma=4.1135 \cdot\left(\frac{c}{d_{50}}\right)^{0.742} \cdot\left(\frac{D_{p}}{d_{50}}\right)^{-0.522} \cdot F_{0}{ }^{-0.682} \\
\Omega=6.9 \cdot 10^{-4} \cdot\left(\frac{c}{d_{50}}\right)^{-4.63} \cdot\left(\frac{D_{p}}{d_{50}}\right)^{3.58} \cdot F_{0}{ }^{4.535} \\
\frac{d_{\infty}^{c}-d_{\infty}^{u}}{d_{\infty}^{u}+h_{p}}+1=1.18 \cdot\left(\frac{X_{w}}{X_{m}^{u}}\right)^{-0.2} \\
X_{m}^{u}=c \cdot F_{0}^{0.94}
\end{gathered}
$$


Being:

$$
\begin{gathered}
F_{0}=\frac{V_{0}}{\sqrt{g \cdot d_{50} \cdot\left(\left(\frac{\rho_{s}}{\rho_{w}}\right)-1\right)}} \\
h_{p}=c+\frac{D_{p}}{2}
\end{gathered}
$$

Being Eqs. (7.1) and (7.2) the proposed by [23] and [13] respectively for unconfined propellers and Eq. (10) the proposed by [8] for confined propellers.

\section{RESULTS}

\section{FIELD CAMPAIGN RESULTS}

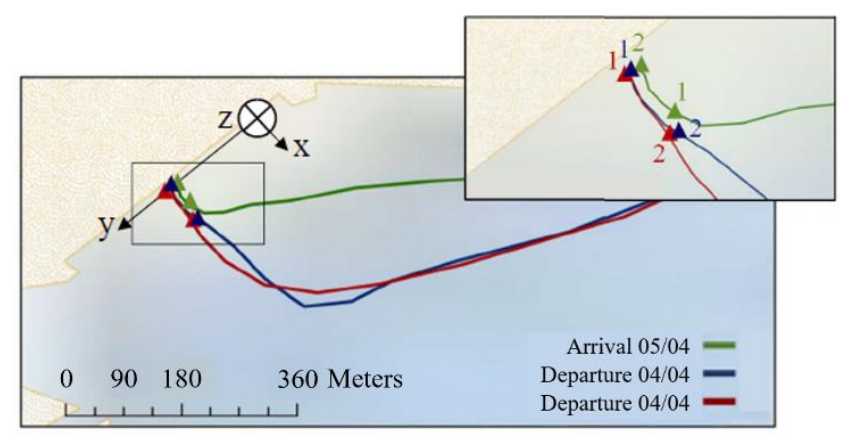

Figure 5. Manoeuvres performed by the study-vessel during the campaign days.

Figure 5 shows the tracked manoeuvres of the study vessel during the measuring campaign. The enlarged area shows the vessel's positions for the time frame in which flow velocity measures gives relevant values. Measured velocities are shown in Figure 6. Velocities on $\mathrm{X}$ axis (transversal to the main quay) are close to 0 during the whole manoeuvre, for both the arrival and the departure. On the $\mathrm{Z}$ axis, velocities are positive during the whole departure manoeuvre, meaning that ADV is measuring a bottom-directed flow. For the arrival manoeuvre, velocities measured on $\mathrm{Z}$ axis are negligible. Most relevant measures have been obtained on the $\mathrm{Y}$ axis, which is longitudinal to the main quay and perpendicular to the back quay. Velocity measures showed maximum bow-directed flow velocity values around 1 $\mathrm{m} / \mathrm{s}$ on this axis. Also, during the arrival manoeuvre, measured velocities for this component change their sign, being negative at the beginning and positive at the end of the manoeuvre, indicating a change on the measured wash direction. Final measures correspond to the last geographical positions, when the ship is already at the final docking position, and the propeller's regime is inverted to stop the inertial movement of the ship when is already at the docking place.

Table 5 shows the maximum measured velocity values per component $(\mathrm{X}, \mathrm{Y}, \mathrm{Z})$ and other relevant values: measures time period, depth and water temperature. Maximum velocities are measured on the departure. Time period is similar for both the arrival and the departure.
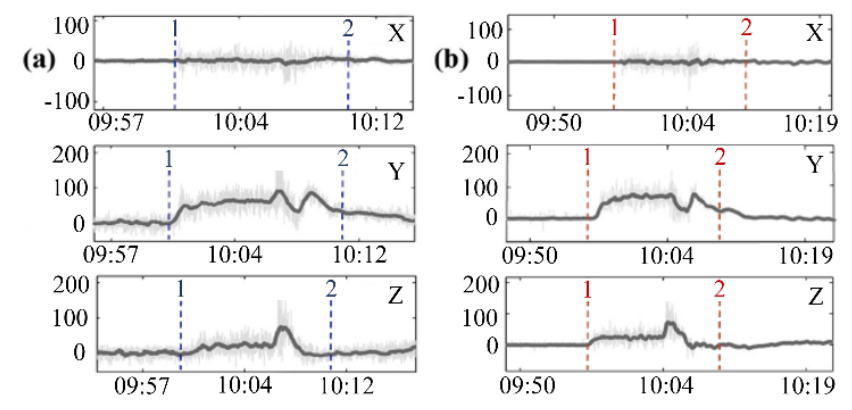

Figure 6. ADV measures (X,Y,Z axis) during the campaign.

a) Departure 04/04;

b) Departure 05/04;

c) Arrival 05/04;
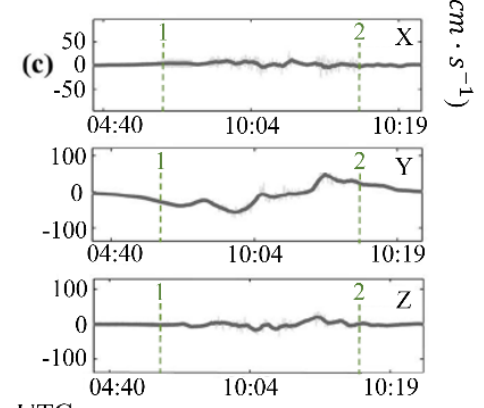

Time UTC

Table 5. ADV measures

\begin{tabular}{cccc}
\hline Variable & $\begin{array}{c}\text { Arrival } \\
\mathbf{0 5 / 0 5}\end{array}$ & $\begin{array}{c}\text { Departure } \\
\mathbf{0 4 / 0 5}\end{array}$ & $\begin{array}{c}\text { Departure } \\
\mathbf{0 5} / \mathbf{0 5}\end{array}$ \\
\hline Depth $(\mathrm{m})$ & 3.1 & 3.1 & 3.1 \\
Temperature $\left({ }^{\circ} \mathrm{C}\right)$ & 16.5 & 16.7 & 16.6 \\
Measures start $(\mathrm{UTC})$ & $04: 44: 17$ & $10: 01: 44$ & $09: 57: 54$ \\
Measures end $(\mathrm{UTC})$ & $05: 53: 26$ & $10: 10: 24$ & $10: 07: 38$ \\
Time $(\mathrm{s})$ & 550 & 520 & 639 \\
Max. Vel. positive $(\mathrm{X})\left(\mathrm{cm} \cdot \mathrm{s}^{-1}\right)$ & 12.2 & 9.2 & 8.4 \\
Max. Vel. negative $(\mathrm{X})\left(\mathrm{cm} \cdot \mathrm{s}^{-1}\right)$ & -4.8 & -10.7 & -9.3 \\
Max. Vel. positive $(\mathrm{Y})\left(\mathrm{cm} \cdot \mathrm{s}^{-1}\right)$ & 51.7 & 90 & 74.7 \\
Max. Vel. negative $(\mathrm{Y})\left(\mathrm{cm} \cdot \mathrm{s}^{-1}\right)$ & -60.4 & - & - \\
Max. Vel. positive $(\mathrm{Z})\left(\mathrm{cm} \cdot \mathrm{s}^{-1}\right)$ & 20.3 & 73.9 & 74.1 \\
Max. Vel. negative $(\mathrm{Z})\left(\mathrm{cm} \cdot \mathrm{s}^{-1}\right)$ & -16.4 & - & - \\
\hline
\end{tabular}

\section{MANEUVER SIMULATOR RESULTS}

Figure 7 shows the simulator performed manoeuvres, according to AIS data obtained during the campaign. It is also shown the propeller's working mode: ahead and astern for the main propellers; inward and outward for the bow thruster.

The evolution of the different variables obtained from the simulator (propeller's rotational speed, engine power and propeller's pitch ratio) as a function of the manoeuvre's time is shown in Figure 8. Negative pitch ratios indicate the propeller is working astern. It's seen that, for negative pitch ratios, the engine power is much bigger than for positive pitch ratios, thus, propeller is less efficient when working astern as assumed during the propeller design. 
The reproduction of the departure manoeuvre shows that the vessel moves in parallel away from the quay for 8 minutes. As in Figure 8, during this time the vessel works with the starboard propeller astern and the port propeller ahead (the first, generating a wash towards the bow and the second, generating it inversely, as in Figure 7 and in accordance to field measures). In addition, the bow thrusters are generating wash inwards, as shown in Figure 7.

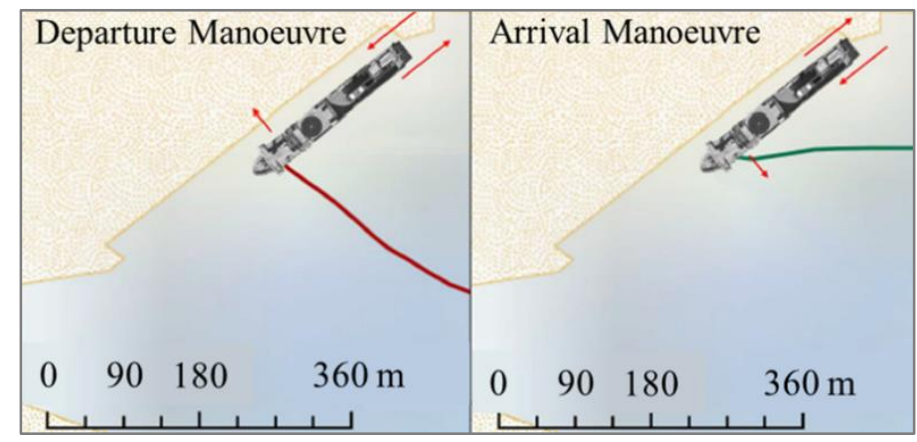

Figure 7. Propellers work mode during arrival and departure manoeuvre.

During the arrival manoeuvre the vessel is manoeuvring with the port propeller astern, the starboard propeller ahead (Figure 8) and the bow thrusters outwards (Figure 7). In this scenario the starboard propeller generated wash is directed towards the back quay, so the measures must be negative on its $\mathrm{Y}$ component, according to the previous section results.
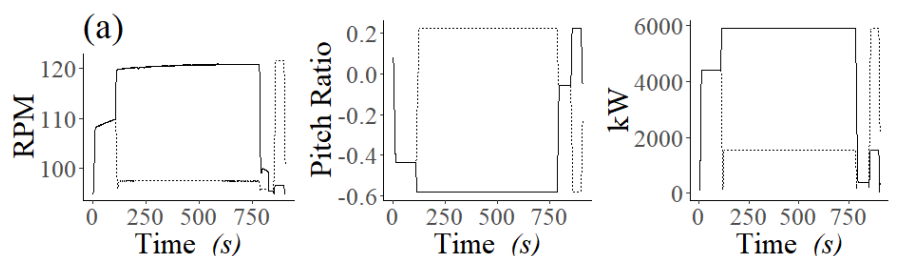

(b)

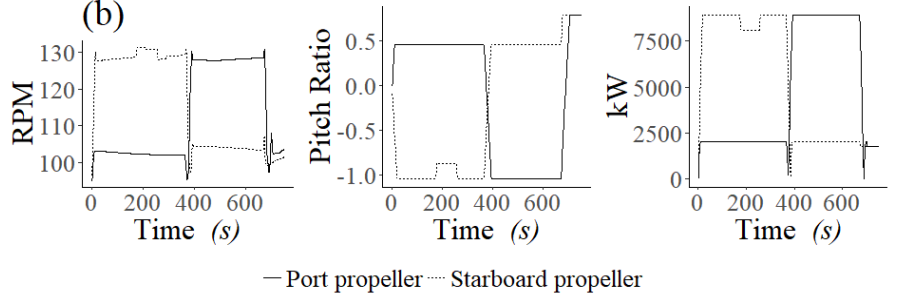

Figure 8. Simulator obtained variable values for (a) arrival and (b) departure manoeuvre.

The Table 6 shows the maximum values obtained from the simulator for each manoeuvre, during the last period of the arrival manoeuvre and the first period of the departure manoeuvre. The arrival manoeuvre has been divided in two time periods because there is a change in the working mode of the propeller during its last part, corresponding to the final positions (near the quay) when the propellers regime is inverted to stop the ship's inertial movement towards the quay.
Table 6. Maximum obtained values from the reproduced maneuvers.

\begin{tabular}{|c|c|c|c|c|c|c|}
\hline \multicolumn{7}{|c|}{ Departure Manoeuvre } \\
\hline $\begin{array}{l}\widehat{\omega} \\
\stackrel{\Xi}{\Xi} \\
\stackrel{\Xi}{\Xi}\end{array}$ & 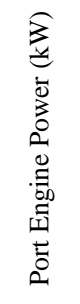 & 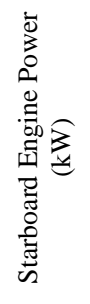 & 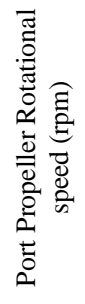 & 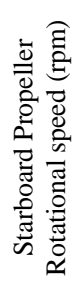 & 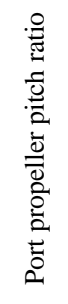 & 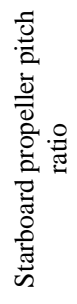 \\
\hline $0-350$ & 2025 & 8930 & 103 & 130 & 0.5 & -1 \\
\hline \multicolumn{7}{|c|}{ Arrival Manoeuvre } \\
\hline 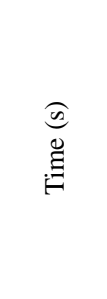 & 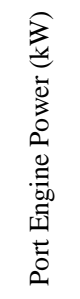 & 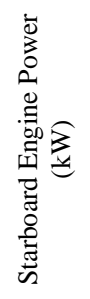 & 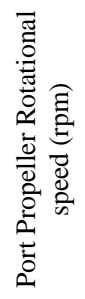 & 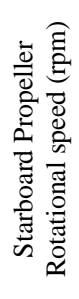 & 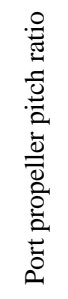 & 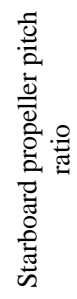 \\
\hline $700-788$ & 5905 & 1540 & 121 & 97 & -0.6 & 0.25 \\
\hline $788-900$ & 3680 & 5905 & 106 & 121 & 0.25 & -0.6 \\
\hline
\end{tabular}

\section{FORMULATION RESULTS}

\section{Propeller-generated wash velocities}

(a)

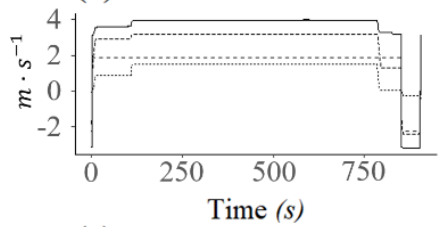

(c)

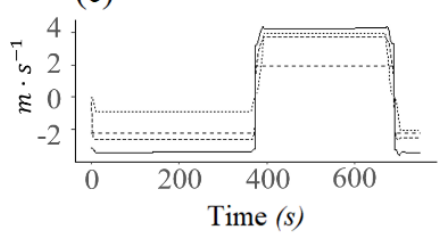

(b)

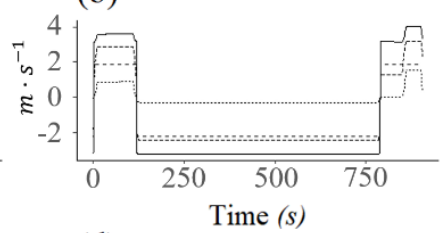

(d)

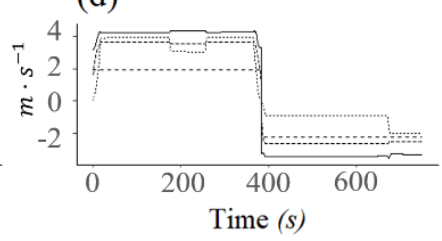

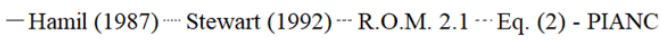

Figure 9. Efflux velocity per author: a) Arrival Manoeuvre, Port propeller; b) Arrival Manoeuvre, Starboard propeller; c) Departure Manoeuvre, Port propeller; d) Departure Manoeuvre, Starboard propeller.

Figure 9 shows the results obtained after the application of the efflux velocity formulae, for each propeller and each manoeuvre. Velocity sign appears in accordance with measured velocity values, being positive velocities ( $\mathrm{Y}$ axis) if the propeller is 
working astern (bow directed wash) and negative velocities (Y axis) if the propeller is working ahead (back quay directed wash).

Efflux velocity formulae should be applied for propellers working ahead, so negative velocities should be taken into consideration, but positive velocities are probably overestimated due to efficiency loses when the propeller is working astern, thus, positive velocities shall not be considered.

Table 7 shows maximum velocity values (negative velocities), which are the maximum axial velocities of the back quay directed wash (propellers working ahead) for the period in which the vessel is near the quay: first and last 120 seconds, for departure and arrival manoeuvre respectively, according to the AIS measures and the simulator results.

Table 7. Efflux velocity maximum values $\left(m \cdot \mathrm{s}^{-1}\right)$

\begin{tabular}{|c|c|c|c|c|}
\hline & 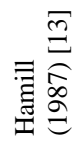 & 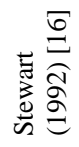 & 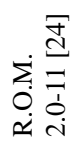 & 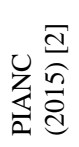 \\
\hline $\begin{array}{l}\text { Port propeller } \\
\text { Arrival manoeuvre }\end{array}$ & 6.7 & 0.6 & 5 & 4.7 \\
\hline $\begin{array}{l}\text { Port propeller } \\
\text { Departure manoeuvre }\end{array}$ & 7.5 & 4.4 & 5.5 & 4.6 \\
\hline $\begin{array}{l}\text { Starboard propeller } \\
\text { Arrival manoeuvre }\end{array}$ & 6.8 & 0.6 & 5 & 4.7 \\
\hline $\begin{array}{l}\text { Starboard propeller } \\
\text { Departure manoeuvre }\end{array}$ & - & - & - & \\
\hline
\end{tabular}

Arrival Maneuver

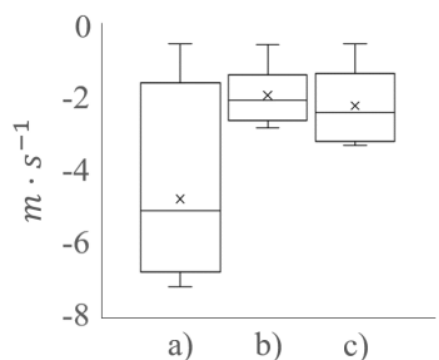

Departure Maneuver

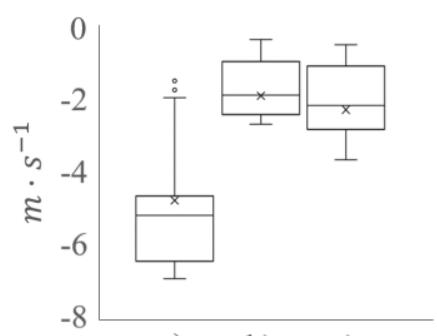

a) b) c)
Figure 10. Velocities calculated at points of interest: a) efflux velocity; b) velocity at the vertical quay; c) velocity at seabed.

Velocities obtained for every formulation (back quay directed fluxes -propellers ahead-) have been plotted in Figure 10. Main differences between arrival and departure manoeuvres are found in the efflux velocity results, which show major variability for the arrival manoeuvre. However, average velocity values are very similar (between 4 and $5 \mathrm{~m} / \mathrm{s}$ ) for both the arrival and departure manoeuvre, indicating similar erosive forcing for both manoeuvres. Velocities calculated at the vertical quay and at the seabed are also similar for both the arrival and departure manoeuvre, showing maximum values around $3 \mathrm{~m} / \mathrm{s}$ and average values around $2 \mathrm{~m} / \mathrm{s}$.

\section{Propeller generated scour}

With the obtained results from the simulator and the data provided by the Port Authority, formulae proposed by [23] and [8] is used to calculate the potential scouring action in the conditions the vessel is currently operating. Method proposed by [8] considers that the scouring action produced near a vertical structure is an alteration of the original profile, the one which would be generated without the vertical structure.

Table 8 shows the considered variables which have been used to apply the formulation. Jet's adimensional Reynolds coefficient $\left(R_{e j}\right)$ is over the threshold obtained by [25], so the effects of viscosity can be negligible.

Results obtained by the application of scouring formulae are shown for both the arrival and departure manoeuvre in Figure 11. Final value which maximum erosion tends to, arrives to an asymptotic state when the erosion is between 6 and $7.5 \mathrm{~m}$, for the considered sediment density range. According to [8], the erosion depth value should have a precision of $\pm 10 \%$, which would lead erosion values between 5.5 and $8 \mathrm{~m}$. Obtained values have to be summed to the initial $12 \mathrm{~m}$ depth, so final depths should be between 17.5 and $20 \mathrm{~m}$ (considering $10 \%$ uncertainty), which is a similar depth range than the obtained from the previously showed bathymetry (14-17 m).

Table 8. Considered variables in erosion calculation formulae

\begin{tabular}{llrr}
\hline \multicolumn{4}{c}{ Considered variables } \\
\hline $\mathrm{D}_{\mathrm{p}}(\mathrm{m})$ & 5.1 & $\mathrm{X}_{\mathrm{w}}(\mathrm{m})$ & 28 \\
Num. blades & 4 & $\rho_{\mathrm{s}}\left(\mathrm{mt} \cdot \mathrm{m}^{-3}\right)$ & $1.8-2.2$ \\
B.A.R [-] & 0.45 & $\rho_{\mathrm{w}}\left(m t \cdot \mathrm{m}^{-3}\right)$ & 1.025 \\
$\mathrm{n}(\mathrm{rpm})$ & $103-109$ & $\mathrm{~h}_{\mathrm{p}}(\mathrm{m})$ & 8.9 \\
$\mathrm{C}_{\mathrm{t}}[-]$ & 0.38 & $v\left(\mathrm{~m}^{2} \cdot \mathrm{s}^{-1}\right)$ & $1.19 \cdot 10^{-6}$ \\
$\mathrm{~F}_{0}[-]$ & $33-45$ & $\mathrm{R}_{\mathrm{ej}}[-]$ & $>10^{4}$ \\
$\mathrm{~d}_{50}(\mathrm{~mm})$ & 2 & $\mathrm{~T}\left({ }^{\circ} \mathrm{C}\right)$ & 16 \\
\hline
\end{tabular}

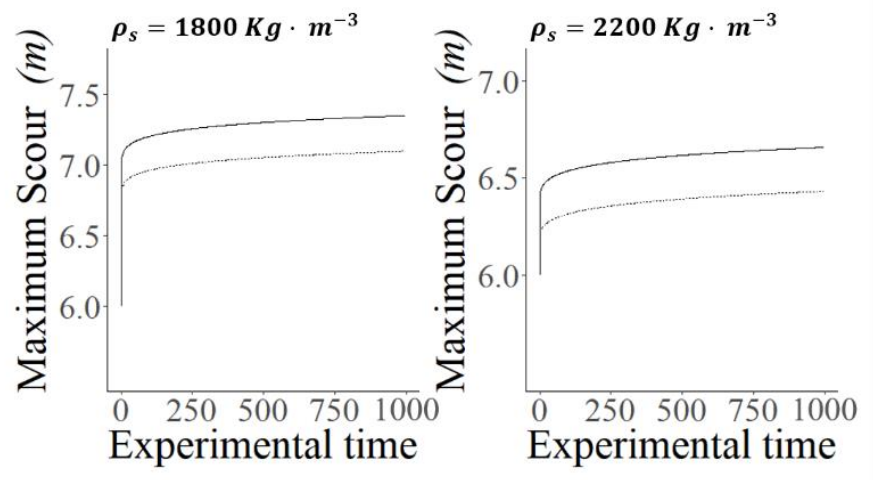

-Departure Maneuver (Eq. 7.1)-Arrival Maneuver (Eq. 7.1)

Figure 11. Erosion depth results for different sediment densities. 


\section{DISCUSSION}

ADV measuring system is found to be a good tool to measure propeller-generated current velocities and, when combined with AIS data, it is possible to obtain the geographical positions and orientation of the vessel when the currents are maximum and, consequently, more harmful.

Even though the numerical simulator has permitted to obtain variables that otherwise could not have been obtained, these results simplify the reality as they don't take into consideration possible rudder or bow thruster effects, which have been maintained at constant regime to prevent the results to be affected by non-considered variables. [4], [23], [26], describe the effects of the rudder position on the direction and magnitude of the issued flow. They confirmed the formation of two high velocity streams (one upwards and the other downwards) increasing the axial velocity by as much as $30 \%$. Thus, a safety factor should be considered when formulae for propellers without rudder is applied.

[3] concludes that theoretical limitations make momentum theory non-representative of the reality and suggest a new equation, much more dependent on the propeller physical and behavioural characteristics. It is considered, so, a valid approach for laboratory studies where the availability of all the variables makes it wearable. However, when trying to obtain values on field, momentum theory derived formulae is considered useful to obtain a good approximation of propeller-induced wash velocities.

Once the results are examined it is seen that the behaviour of the generated fluxes coincides with the current measures obtained during the campaign and previously showed in this article. Departure manoeuvre formulae results show positive flux during the first part of the manoeuvre, while the arrival manoeuvre results show a first negative flux period and a second positive flux period, as measured at field. However, ADV measurer, positioned ahead of the starboard propeller during the campaign, measured bow directed flux generated by the propeller working astern. As it is known, formulae are proposed for propellers working ahead, so it must be estimated an efficiency loss factor for the mentioned condition. Regardless of the efficiency loses, measures ahead the propellers are also affected by other factors such as interaction between the ship hull and the flow, so the difference between expected velocity and measured velocity cannot be considered just an efficiency loss. Also, inverted propellers working at the same time can generate opposite fluxes which interact with each other. Literature proposes the quadratic superposition [2], [18], in case both propellers are working with the same regime (ahead), but there is no literature regarding propellers working at inverse regime.

When quantifying the generated scour, the formulation proposed by [8], [13], [23] provides a value of the scour as a function of time, but restricted to an experimental time in which an asymptotic state is reached (threshold of the $1 \%$ variance). In [8] a new formulation for the non-confined scouring action is proposed in order to apply, later, the confined scour formulation. Formulations proposed by [6] and [13] (non-confined scour), combined with confined scour formulation proposed by [8] gave reasonable values, however, proposed combination of nonconfined and confined formulae in [8] gave values which do not represent the real case. This results show accordance with results obtained by [1], from another Mediterranean port and RO-RO vessel, where new formulae from [8] were neither representative of the real case. In the experiments realized by [8] the relation between the wall clearance and the maximum scour point is never less than 0.636 , while it is 0.05 in the study case. However, the seabed clearance limitations are totally fulfilled $\left(C>0.5 D_{p}\right.$ and $C<2.5 D_{p}$ ). More research is needed to figure out the real limitations of the formulae when applied out of the laboratory.

Also, it must be considered that used variables and some data must be re-examined, such as a more recent bathymetry and a concise sediment characterization to apply the formulae and check the results. Obviously, [8] formulae is highly dependent on the sediment characterisation, which has been poorly detailed for this study due to lack of data. However, results do show potential to re-examine the question in other similar studies.

\section{CONCLUSIONS}

- Vessel's manoeuvre study allows the reproduction and the data obtaining to apply the existing formulae, for characterising both the generated currents and the scouring action.

- $\quad$ On the study conditions, a typical RO-RO would cause an erosion depth between 6 and $7 \mathrm{~m}$.

- Erosion obtained values are considered a good approximation to the real case values, however, with a better sediment characterisation it could provide more reliable results.

- No considerable differences have been found between the scouring effects on arrival and departure manoeuvre for the study conditions.

- The performance of periodic bathymetries would help to control the evolution of the seabed and would permit to re-examine the results.

- The use of the simulator allows to reproduce any manoeuvre with any met-ocean condition, so the results obtained can help to manage the port resources depending on them.

- More experimental study is needed regarding the behaviour of twin propellers at inverse regimes, a common condition in most of the manoeuvres.

\section{NOMENCLATURE}
B.A.R. Blade Area Ratio (-);
c 


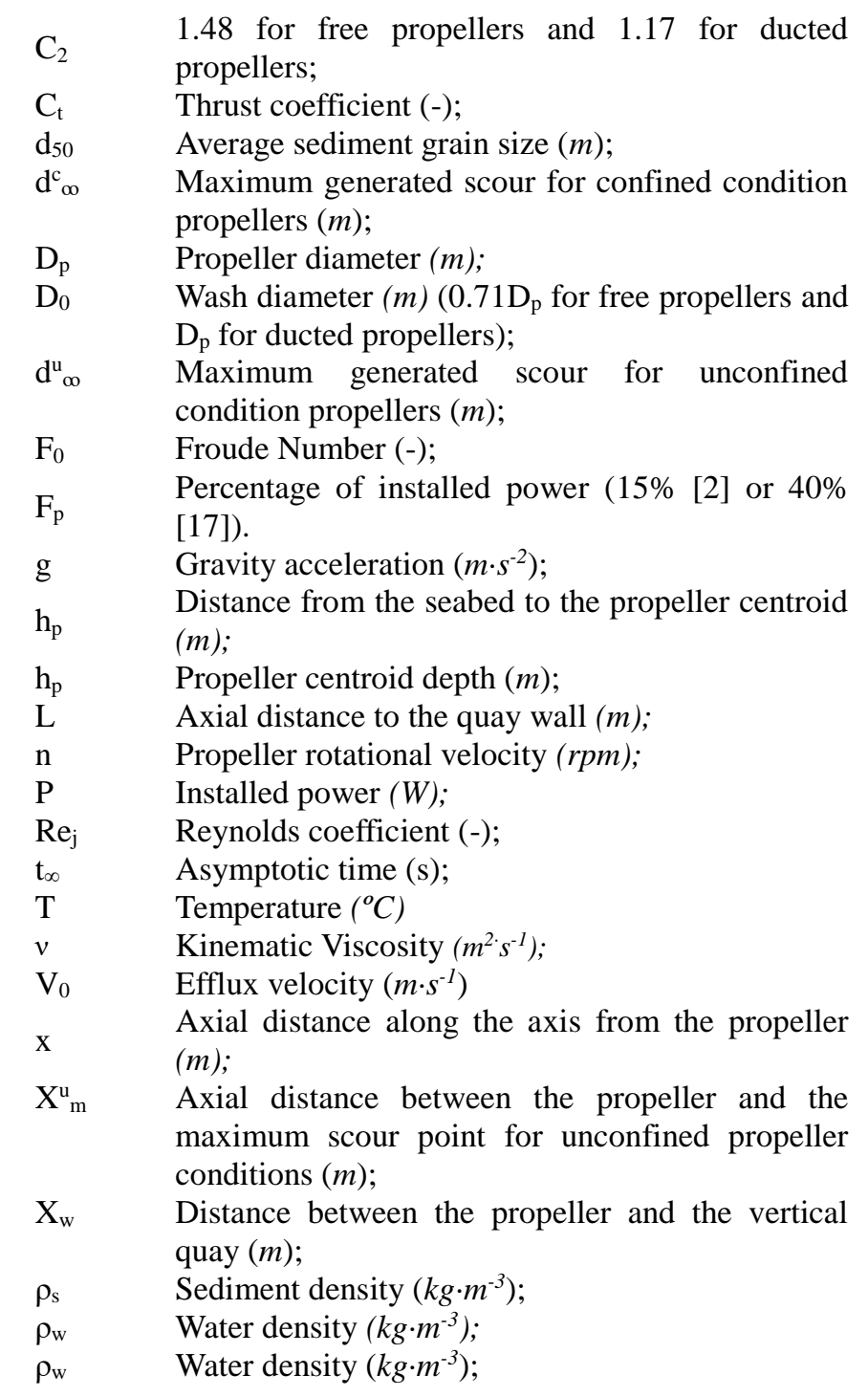

\section{ACKNOWLEDGMENTS}

We greatly acknowledge the technical staff of the UPC CIEMLAB for their support throughout the experiments. This work has been supported by MINECO (Ministerio de Economía y Competitividad) and FEDER (Unión Europea- Fondo Europeo de Desarrollo Regional "Una Manera de hacer Europa") from Spanish Government through project BIA2012-38676-C03-01 and TRA2015-70473-R.

\section{REFERENCES}

[1] A. Mujal-Colilles, X. Gironella, A. Sanchez-Arcilla, C. Puig Polo, and M. Garcia-Leon, "Erosion caused by propeller jets in a low energy harbour basin," J. Hydraul. Res., vol. 55, no. 1, pp. 121-128, 2017.

[2] PIANC, Guidelines for protecting berthing structures from scour caused by ships. Report $n^{\circ} 180$. The World Association for Waterborne Transportation
Infrastructure, 2015.

[3] G. Hamill, J. A. Mcgarvey, and D. A. B. Hughes, "Determination of the efflux velocity from a ship's propeller," no. June 2004, pp. 83-91, 2010.

[4] G. A. Hamill, J. A. M. Garvey, and P. A. Mackinnon, "A method for estimating the bed velocities produced by a ship's propeller wash influenced by a rudder .," pp. 3624-3633, 1998.

[5] H. N. Hashmi, "Propeller-Wash Induced Erosion and Method for Its Prediction," Taxila, 2007.

[6] G. Hamill, C. Kee, and D. Ryan, "Three-dimension efflux velocity characteristics of marine propeller jets," Proc. Inst. Civ., vol. 168, no. 2015, pp. 62-75, 2015.

[7] D. Ryan and G. a. Hamill, "Determining Propeller Erosion at the Stern of a Berthing Ship," J. Waterw. Port, Coastal, Ocean Eng., no. August, p. 104, 2012.

[8] G. Hamill, H. T. Johnston, and D. Stewart, "Propeller Wash Scour Near Quay Walls," J. Waterw. Port, Coast. Ocean Eng., vol. 125, no. 4, pp. 170-175, 1999.

[9] D. Ryan, G. Hamill, and H. Johnston, "Determining propeller induced erosion alongside quay walls in harbours using Artificial Neural Networks," Ocean Eng., vol. 59, pp. 142-151, 2013.

[10] H. Symonds, A.; Britton, G.; Donald, J.; Loehr, "Predicting propeller wash and bed disturbance by recreational vessels at marinas," PIANC, pp. 170-178, 2015.

[11] M. Fuehrer, H. Pohl, and K. Römish, "Propeller jet erosion and stability criteria for bottom protections of various constructions," Bull. Perm. Int. Assoc. Navig. Congr., vol. 58, 1987.

[12] H. Verhey, "1983-The stability of bottom and banks subjected to the velocities in the propeller jet behind ships.pdf," Int. Harb. Congr. 8th., 1983.

[13] G. Hamill, "Characteristics of the screw wash of a manoeuvring ship and the resulting bed scour.," Dr. Diss. Queen's Univ. Belfast, 1987.

[14] Puertos del Estado, "Obras de Atraque y Amarre: Criterios generales y Factores del Proyecto.," R.O.M. 0290, 1990.

[15] Puertos del Estado, "Conjunto de datos: REDMAR." Puertos del Estado.

[16] D. P. J. Stewart, "Characteristics of a ship's screw wash and the influence of quay wall proximity," Dr. Diss. Queen's Univ. Belfast, 1992.

[17] Puertos del Estado, "Obras de Atraque y Amarre: Criterios generales y Factores del Proyecto (R.O.M. 2.011)," 2012.

[18] A. Mujal-Colilles, X. Gironella, A. Jaquet, R. GomezGesteira, and A. Sanchez-Arcilla, "Study of the Efflux Velocity Induced By Two Propellers," in SCACR, Conference on Applied Coastal Research, 2015.

[19] M. L. Albertson, Y. B. Dai, and R. A. Jensen, "Diffusion of submerged jets," Trans. Am. Soc. Civ. Eng., vol. 115, no. 1, pp. 639-664, 1950.

[20] J. de Jong, "Numerical Modelling of Bow Thrusters at 
Open Quay Structures,” no. January, pp. 1-126, 2014.

[21] H. G. Blaauw and E. J. van de Kaa, "Erosion of Bottom and Sloping Banks Caused by the Screw Race of Manoeuvring Ships, Publication N. 202," 7th Int. Harb. Congr. Antwerp, Belgium, vol. 202, no. 1978.

[22] R. H. Blokland, T., \& Smedes, "In situ tests of current velocities and stone movements caused by a propeller jet against a vertical quay wall.," Proc. 11th Int. Harb. Congr. Antwerp, Belgium., 1996.

[23] G. Hamill, "The scouring action of the propeller jet produced by a slowly manoeuvring ship," Bull. Perm. Int. Assoc. Navig. Congr., vol. 62, 1988.

[24] Puertos del Estado, "Obras de Atraque y Amarre: Criterios generales y Factores del Proyecto (R.O.M. 2.011)," R.O.M. 2.0-11, 2012.

[25] N. Rajaratnam, "Erosion By Plane Turbulent Jets," J. Hydraul. Res., vol. 19, no. 4, pp. 339-358, 1981.

[26] G. Hamill and J. A. McGarvey, "Designing for propeller action in harbours," Coast. Eng. Proc., vol. 1, no. 25, pp. 4451-4463, 1996. 